\title{
Fatigue Behavior of Dissimilar Al-Mg-Si/Al-Zn-Mg Aluminum Alloys Friction Stir Welding Joints
}

\author{
Zhong-Jie Yan ${ }^{1} \cdot$ Xue-Song Liu ${ }^{1} \cdot$ Hong-Yuan Fang ${ }^{1}$
}

Received: 14 September 2016/Revised: 10 October 2016/Published online: 4 November 2016

(C) The Chinese Society for Metals and Springer-Verlag Berlin Heidelberg 2016

\begin{abstract}
In this study, fatigue properties and fracture mechanism of dissimilar $\mathrm{Al}-\mathrm{Mg}-\mathrm{Si} / \mathrm{Al}-\mathrm{Zn}-\mathrm{Mg}$ aluminum alloys friction stir welding (FSW) joints were investigated and the effect of the sheet configuration on the fatigue behavior of the FSW joints was also discussed. Results showed that the joints owned better fatigue properties when the $\mathrm{Al}-\mathrm{Zn}-\mathrm{Mg}$ aluminum alloy was placed at the advancing side (AS). At $10^{7}$ cycles, the fatigue strengths of $\mathrm{Al}-\mathrm{Zn}-\mathrm{Mg}-\mathrm{AS}$ and $\mathrm{Al}-\mathrm{Mg}-$ $\mathrm{Si}-\mathrm{AS}$ joints were, respectively, 105.6 and $90.1 \mathrm{MPa}$. All joints fractured at the heat-affected zone at the $\mathrm{Al}-\mathrm{Mg}-\mathrm{Si}$ alloy side. Transmission electron microscopy results showed that better fatigue property of the $\mathrm{Al}-\mathrm{Zn}-\mathrm{Mg}-\mathrm{AS}$ joint was associated with the bridging effect of the bigger secondary phase particles.
\end{abstract}

\section{KEY WORDS: Fatigue behavior; Friction stir welding; Al-Mg-Si/Al-Zn-Mg aluminum alloys; Secondary phase particle}

\section{Introduction}

Owning various advantages of lower residual stress, smaller distortion and less defects, friction stir welding (FSW) joints have been extensively studied by researchers and widely used to modern industries $[1,2]$. FSW was initially invented to join aluminum alloys, which are traditionally considered as difficult to weld using traditional fusion welding technologies. As a solid-state joining technology, FSW has also shown great potential in welding other materials, such as $\mathrm{Mg}$ alloys, steel and $\mathrm{Ti}$ alloys [3-5]. Moreover, plenty of papers have focused on FSW joints of dissimilar alloys, such as $\mathrm{Al} / \mathrm{Ti}$ [6], Al/Steel [7] and $\mathrm{Al} / \mathrm{Mg}$ [8] joints in recent years. For FSW of dissimilar

Available online at http://link.springer.com/journal/40195.

Xue-Song Liu

hit_lxs@163.com

1 State Key Laboratory of Advanced Welding and Joining, Harbin Institute of Technology, Harbin 150001, China aluminum alloys, the joints not only combine the advantages of the two base materials (BMs), such as low densities, high strengths and good corrosion resistances, but also avoid the formation of thick brittle intermetallic compounds (IMCs), which always own low ductility and deteriorates the joints mechanical properties $[8,9]$.

In actual engineering applications, the fatigue reliability of the FSW joints is one of the major concerns in determining the in-service life of the structural components [10]. Traditionally, the FSW joint can be divided into several regions based on the microstructure features after welding: the BM, the heat-affected zone (HAZ), the thermo-mechanically affected zone (TMAZ) and the stir zone (SZ). Microstructures of these zones show much heterogeneity, inevitably resulting in the complexity of the mechanical properties at joint different regions [11, 12]. Hence, the fatigue properties of the FSW joints have been investigated by many researchers [13-17]. Deng et al. [10] found out that the fatigue properties of 7050-T7451 aluminum alloy FSW joint was superior to the BM and most fatigue cracks initiated at the TMAZ and HAZ at the advancing side (AS). Dai et al. [13] found out the highest fatigue crack 
propagation rate in the $\mathrm{SZ}$, which owned fine and equiaxed grains. D'Urso et al. [14] reported that the fatigue crack growth in the SZ was always slower than that in the BM at low stress intensity factor range and the volume defect caused five times higher propagation rate than the BM. Moreover, fatigue properties of other alloys FSW joint and even lap joints were investigated by researchers [15-20].

By contrast, plenty of papers have focused on fatigue properties of similar aluminum alloy FSW joints. But the researches about fatigue properties of dissimilar aluminum alloys are relatively few. $\mathrm{Al}-\mathrm{Mg}-\mathrm{Si}$ and $\mathrm{Al}-\mathrm{Zn}-\mathrm{Mg}$ aluminum alloys are two common structural materials, which are widely applied to modern industries. For instance, Al$\mathrm{Mg}-\mathrm{Si}$ alloys can be used as the side walls and floors of some certain structures due to good corrosion resistance and weld-ability [21], while $\mathrm{Al}-\mathrm{Zn}-\mathrm{Mg}$ alloys were always used as the frame and beam owing to high strengths and good thermostabilities [22]. Therefore, in the present study, fatigue behaviors of $\mathrm{Al}-\mathrm{Mg}-\mathrm{Si} / \mathrm{Al}-\mathrm{Zn}-\mathrm{Mg}$ dissimilar aluminum alloys FSW joints were mainly discussed. Due to different material deformation behaviors of the AS and retreating side (RS) during welding, effect of sheet configuration on joint fatigue properties was also discussed.

\section{FSW Experiment and Fatigue Test}

In the present study, $\mathrm{Al}-\mathrm{Mg}-\mathrm{Si} / \mathrm{Al}-\mathrm{Zn}-\mathrm{Mg}$ aluminum alloys were chosen as the BM. Chemical compositions and mechanical properties of the two materials are listed in Tables 1 and 2. Dimensions of the sheets are machined to $300 \mathrm{~mm} \times 200 \mathrm{~mm} \times 15 \mathrm{~mm}$. Before welding, all sheets were cleaned with sandpapers to clean off the oxidation layer. Diameter of the rotating tool is $35 \mathrm{~mm}$. Diameters of the pin root and pin bottom are, respectively, 20 and $12 \mathrm{~mm}$. Length of the pin is $14.5 \mathrm{~mm}$. During welding, constant rotating and welding speed of $800 \mathrm{rpm}$ and $180 \mathrm{~mm} / \mathrm{min}$ were chosen. Shoulder plunge depth was chosen as $0.2 \mathrm{~mm}$. Titling angle was $2.5^{\circ}$ during welding.

After welding, samples for metallography and fatigue tests were cut perpendicular to the welding line using an electrical discharge cutting machine. Metallographic and fracture surfaces analysis were carried out using a transmission electron microscope (TEM, JEM-2100) and a scanning electron microscope (SEM) equipped with an energy-dispersive spectrometry (EDS) system. Dimension of specimens for the fatigue is shown in Fig. 1 according to GB/T6398-2000. All the specimens were ground and polished before the fatigue tests. The specimens were tested at room temperature with the stress ratio $R=0$ on a PLG200C fatigue testing machine. The frequency adopted during the fatigue tests was $15 \mathrm{~Hz}$. No less than three samples were tested at each load, and the fatigue lives were then averaged.

\section{Results and Discussion}

\subsection{Fatigue Properties}

Figure 2 shows the fatigue lives and S-N curves of the FSW joints using different configurations. For convenience, the joint, in which the $\mathrm{Al}-\mathrm{Mg}-\mathrm{Si}$ aluminum alloy is placed at the $\mathrm{AS}$, is called the $\mathrm{Al}-\mathrm{Mg}-\mathrm{Si}-\mathrm{AS}$ joint. Similarly, Al-Zn$\mathrm{Mg}-\mathrm{AS}$ joint refers to the joint in which the $\mathrm{Al}-\mathrm{Zn}-\mathrm{Mg}$ aluminum alloy is placed at the AS. Based on the fatigue life, the $\mathrm{S}-\mathrm{N}$ curves of the $\mathrm{Al}-\mathrm{Zn}-\mathrm{Mg}-\mathrm{AS}$ and $\mathrm{Al}-\mathrm{Mg}-\mathrm{Si}-\mathrm{AS}$ joints are listed as $\log S=2.96241 \cdot \log N-0.341$ and $\log S=3.18763 \cdot \log N-0.17615$. The goodness-of-fit values are, respectively, 0.930 and 0.933 , illustrating the accuracy of the S-N curves. It can be seen that the Al-Zn$\mathrm{Mg}-\mathrm{AS}$ joints own better fatigue properties than the $\mathrm{Al}-\mathrm{Mg}-$ $\mathrm{Si}-\mathrm{AS}$ joints. At $10^{7}$ cycles, the fatigue strengths of Al-Zn$\mathrm{Mg}-\mathrm{AS}$ and $\mathrm{Al}-\mathrm{Mg}-\mathrm{Si}-\mathrm{AS}$ joint are 105.6 and 90.1 MPa, respectively.

During the fatigue tests, all joints fractured at the HAZ regions at the $\mathrm{Al}-\mathrm{Mg}-\mathrm{Si}$ side. Figure 3 shows the general views of the fracture surfaces on different joints. It can be seen that all the crack propagation regions present semicircle morphologies. After initiating from the crack source, crack gradually propagates under the repeated fluctuating load, reducing the load-bearing area of the specimen. When reaching the critical fracture toughness, the joint fractured, forming final rupture region. With increasing the stress, critical length of the crack decreases, crossing the section of the crack propagation region. As shown in Fig. 3b and c, critical length decreases from 10.7 to $8.8 \mathrm{~mm}$ when the stress increases from 140 to $160 \mathrm{MPa}$.

Formation of the macro-fatigue crack can be divided into four stages: the formation of the micro-crack, the

Table 1 Chemical compositions of the BM (wt $\%$ )

\begin{tabular}{llllllllll}
\hline $\mathrm{BM}$ & $\mathrm{Si}$ & $\mathrm{Fe}$ & $\mathrm{Cu}$ & $\mathrm{Mn}$ & $\mathrm{Mg}$ & $\mathrm{Zn}$ & $\mathrm{Ti}$ & $\mathrm{Cr}$ & $\mathrm{Al}$ \\
\hline $\mathrm{Al}-\mathrm{Mg}-\mathrm{Si}$ & $0.4-0.9$ & $\leq 0.35$ & $\leq 0.35$ & $\leq 0.50$ & $0.4-0.8$ & $\leq 0.25$ & $\leq 0.10$ & $\leq 0.30$ & Bal. \\
$\mathrm{Al}-\mathrm{Zn}-\mathrm{Mg}$ & $\leq 0.30$ & $\leq 0.30$ & $\leq 0.20$ & $0.2-0.7$ & $1.0-2.0$ & $4.0-5.0$ & $\leq 0.20$ & $\leq 0.30$ & Bal. \\
\hline
\end{tabular}


Table 2 Mechanical properties of the BM

\begin{tabular}{llll}
\hline BM & Tensile strength $(\mathrm{MPa})$ & Yield strength (MPa) & Elongation $(\%)$ \\
\hline Al-Mg-Si & 284 & 241 & 25 \\
Al-Zn-Mg & 368 & 256 & 19.5 \\
\hline
\end{tabular}

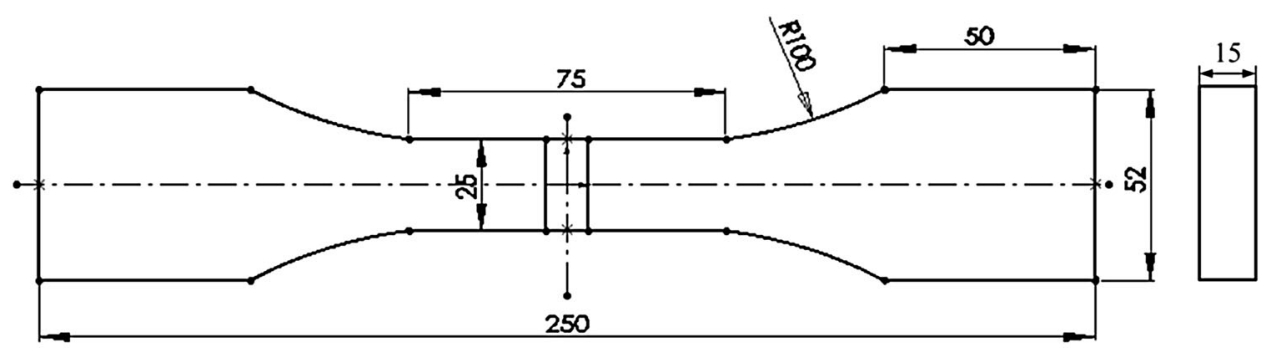

Fig. 1 Dimension of the specimen for fatigue

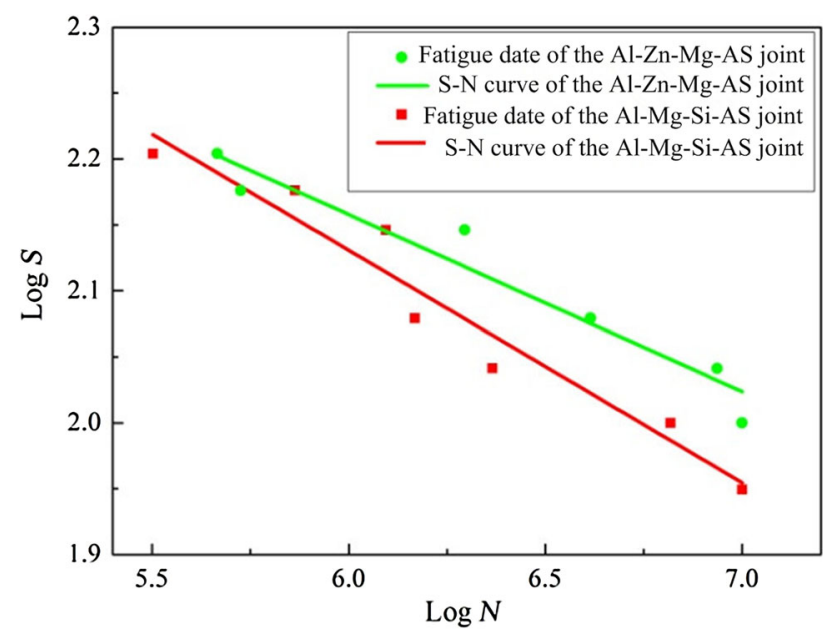

mechanical small crack, the physical short crack and the macro-fatigue crack. These four stages are divided according to crack length, the microstructure and size of the crack tip region. Therein, micro-crack is always formed at the region with highest stress and lowest strength. Figure 4 shows the initiation regions of the micro-crack. It can be seen that the micro-cracks are mainly formed at two regions: surface defects (Fig. 4a, b) and secondary phase particles (Fig. 4c, d). As shown in Fig. 4b, a small surface indentation can be observed on the joint surface, which leads into serious stress concentration and resultant joint failure. Generally speaking, the smooth joint surface should be prepared before the fatigue test. Hence, effects of the surface defect on the fatigue properties are not discussed in this paper.

Fig. 2 Fatigue life of the FSW joints
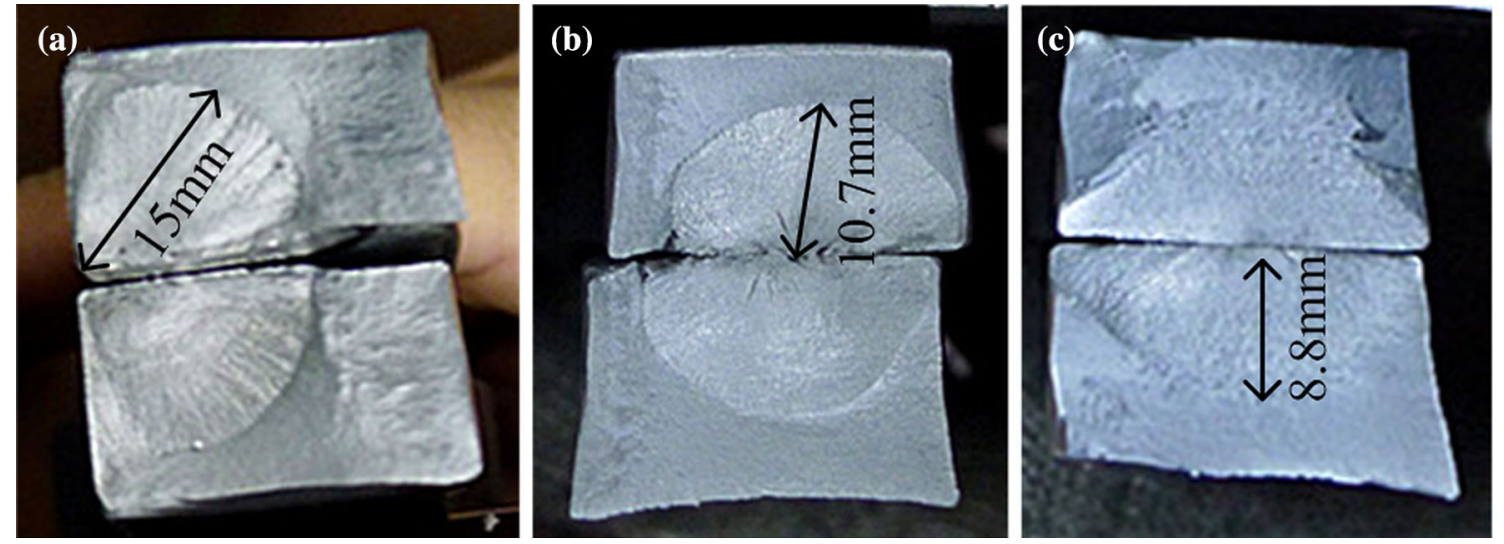

Fig. 3 General views of the fracture surfaces: a Al-Zn-Mg-AS using $120 \mathrm{MPa}$, b Al-Mg-Si-AS using $140 \mathrm{MPa}, \mathbf{c} \mathrm{Al}-\mathrm{Mg}-\mathrm{Si}-\mathrm{AS}$ using $160 \mathrm{MPa}$ 

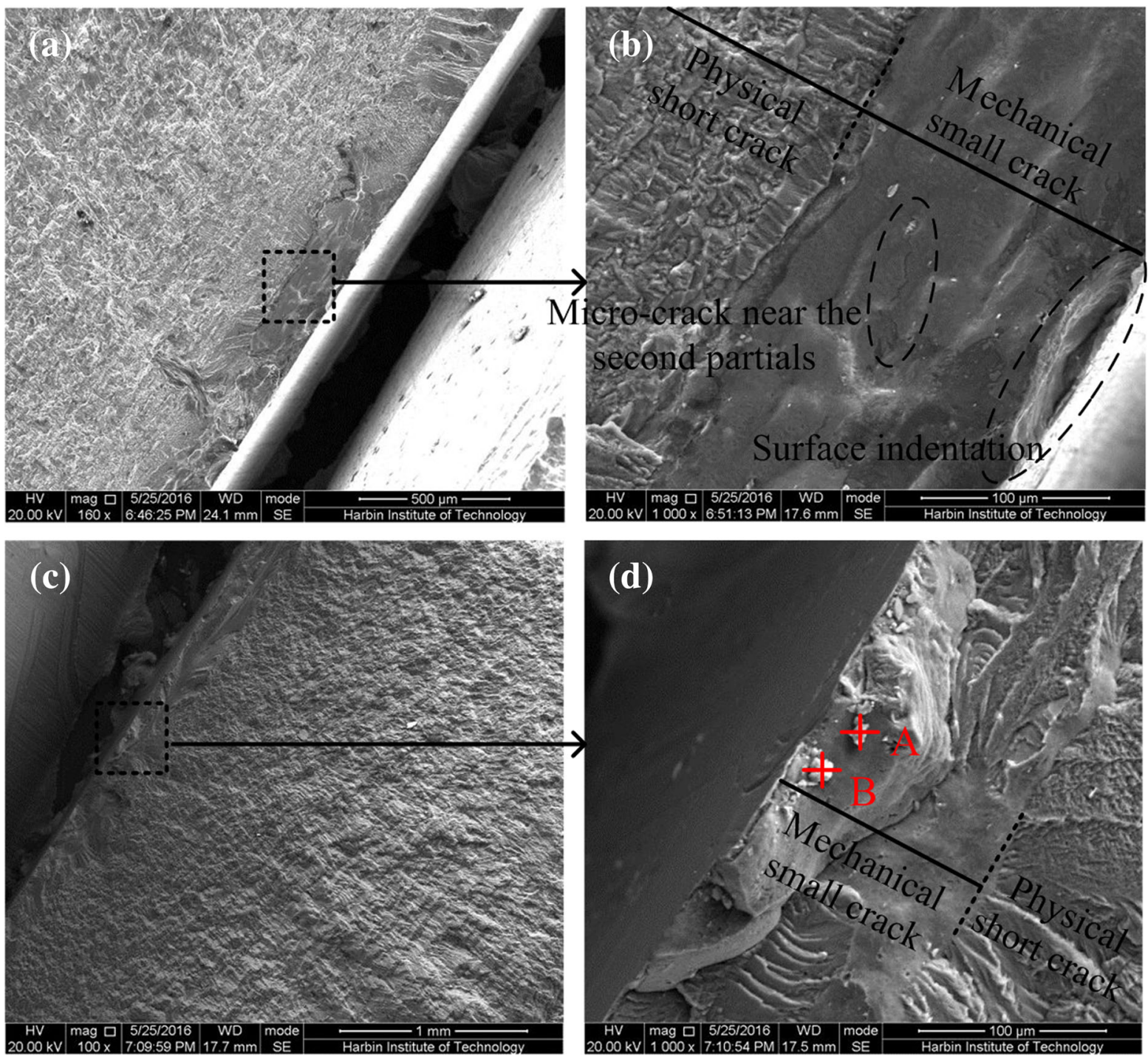

(e)

(f)

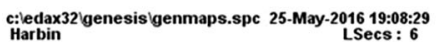

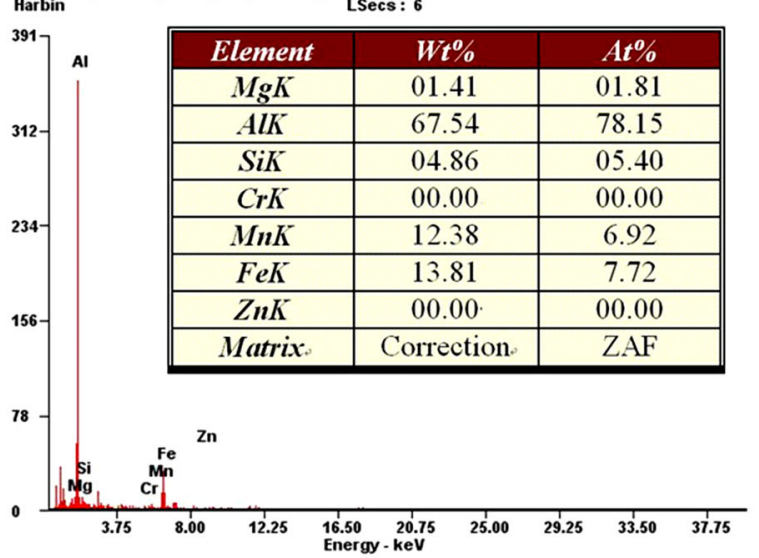

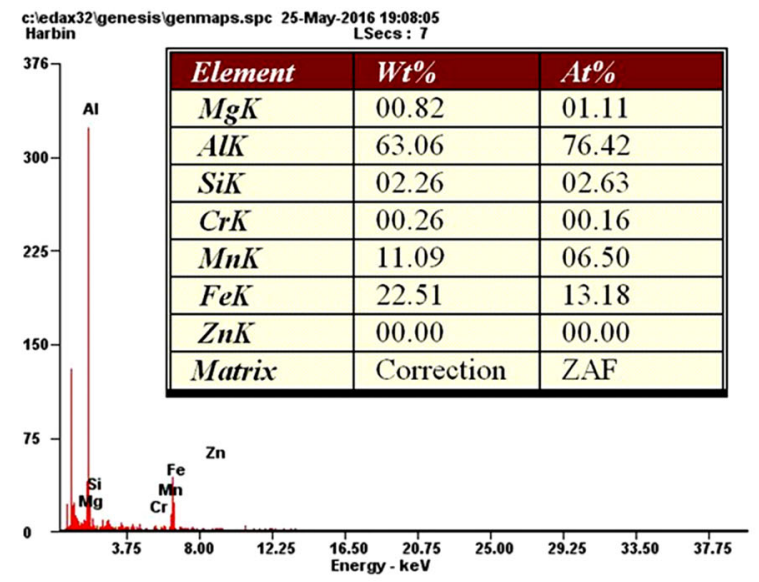

Fig. 4 Crack source: surface indentation a, its magnified view b, secondary phase particle c, its magnified view d, e, $\mathbf{f}$ EDS analyses of the secondary phase particles $A$ and $B$ in $\mathbf{d}$ 
As shown in Fig. 4c, d, another important micro-crack formation region is the secondary phase particle region. Figure $4 \mathrm{e}, \mathrm{f}$ shows the EDS analysis of the second phases. It can be seen that for the $\mathrm{Al}-\mathrm{Zn}-\mathrm{Mg}-\mathrm{AS}$ joint, the main phase is AlFeMnSi phase, which is not coherent with the matrix and belongs to a hard brittle phase. Besides, some of the secondary phase particles own sharp angles, which easily results in local stress concentration. Under alternating stress, some of the secondary phase particles may become the size for crack initiation. Micro-crack can initiate from both the above-mentioned conditions. As shown in Fig. 4d, some secondary phase particles can be observed on the fracture surfaces. Micro-crack about $40 \mu \mathrm{m}$ in length can be observed near the secondary phase particles, as shown in Fig. 4b.

After the micro-crack is formed, it gradually becomes bigger and forms mechanical small crack. Microstructure plays a crucial role during this stage. At the beginning, plastic deformation at the crack tip always happens within the scope of several grains. Under biggest stress, crack propagates in a shearing way, forming new crack.
Figure 4d shows the mechanical small crack. Length of the crack is about $100-200 \mu \mathrm{m}$.

When the mechanical small crack is formed, plastic deformation at the crack tip appeared within rains. Hence, effect of the microstructure on the crack propagation gradually decreases. After that, crack propagates through multi-slip systems and forms physical small crack and then macro-crack. During this period, size of the crack is obviously bigger than plastic deformation at the crack tip. Hence, mechanical factor plays the leading role during the propagation and the fracture surfaces are always perpendicular to the stress direction.

When the macro-crack is formed, crack propagates under the alternating stress. To save energy, crack more easily propagates along the specific grain boundaries which own low propagation energy near the crack tip. Therefore, some radial river-like pattern can be observed, as shown in Fig. 5a. The magnified fracture morphology in Fig. 5b shows some feature morphology, which is composed of some shining tear ridges and small fracture surfaces. Figure $5 \mathrm{c}$ shows the magnified view of the fracture surface
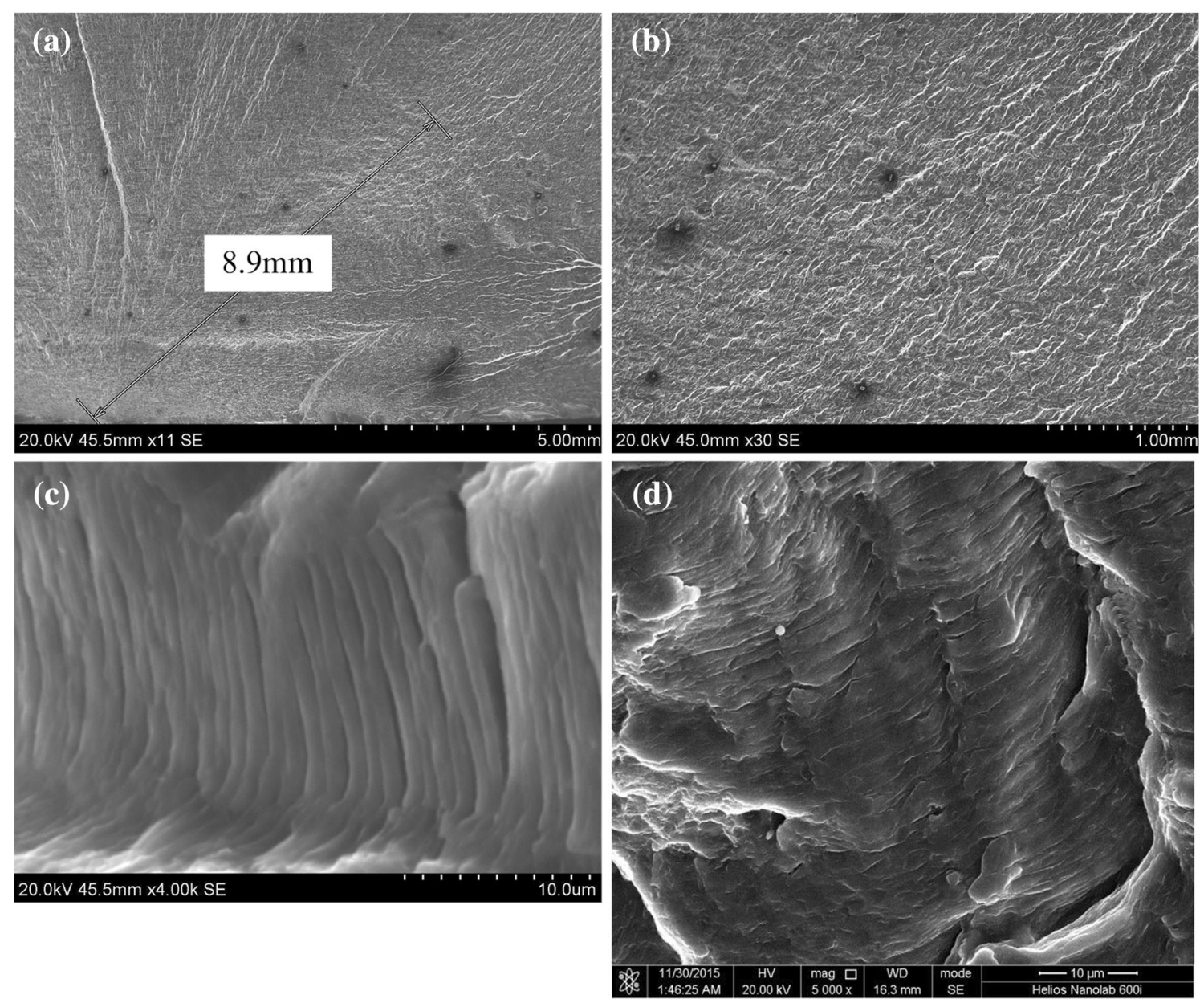

Fig. 5 Radial river-like pattern near the crack source $\mathbf{a}$, its magnified view $\mathbf{b}$, fatigue striations $\mathbf{c}$, micro-pit $\mathbf{d}$ 
which is about $8.9 \mathrm{~mm}$ in length from the crack source. The fracture surface shows typical brittle cleavage fracture mode, on which plenty of fatigue striations can be observed. The fatigue striations show parallel morphologies on the same fracture surface and are perpendicular to the crack propagation direction.

It is worth mentioning that some micro-dimples formed due to coarse secondary phase particles can be observed on fracture surface, as shown in Fig. 5d. As introduced above, secondary phase particles are hard and own sharp angles. They cannot deform conformably with the matrix. During the fatigue test, these secondary phases are the sites forming fracture sources, resulting in formation of the micro-dimples.
Figure 6 shows the fatigue striations observed at different distances from the crack source. It can be seen that the striations spacing gradually become bigger with increasing the distance (from 1 to $3 \mu \mathrm{m}$ ). According to the Paris equation, as the crack propagating, stress intensity factor at the crack tip gradually becomes bigger, resulting in bigger propagating distance per cycle.

Figure 7 shows the fracture morphologies of the final rupture regions of the two joints. Plenty of dimples can be observed on both fracture surfaces. Some secondary phase particles can be observed inside the dimples. It can be seen that the dimples in Fig. 7a are bigger and deeper, indicating better plasticity of the $\mathrm{Al}-\mathrm{Zn}-\mathrm{Mg}-\mathrm{AS}$ joints.
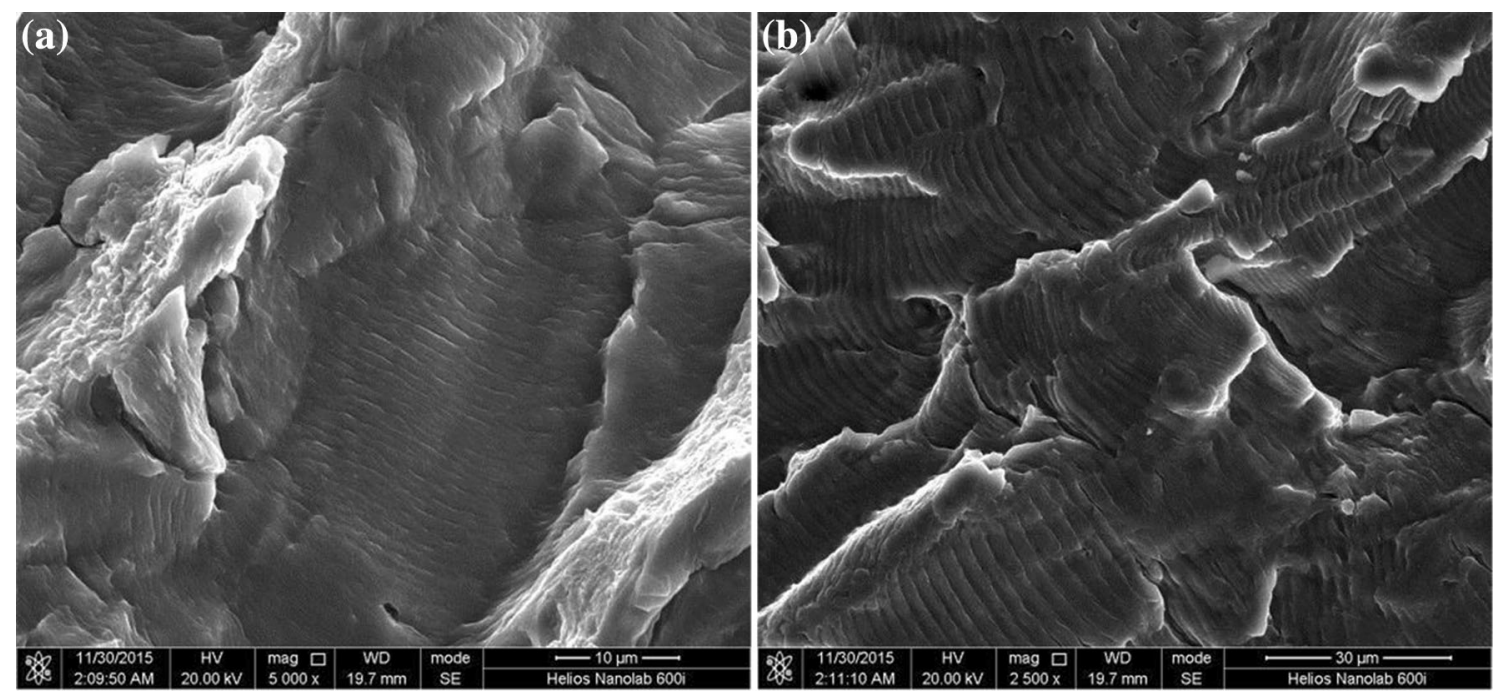

Fig. 6 Fatigue striations near the crack source $\mathbf{a}$, far from the crack source $\mathbf{b}$
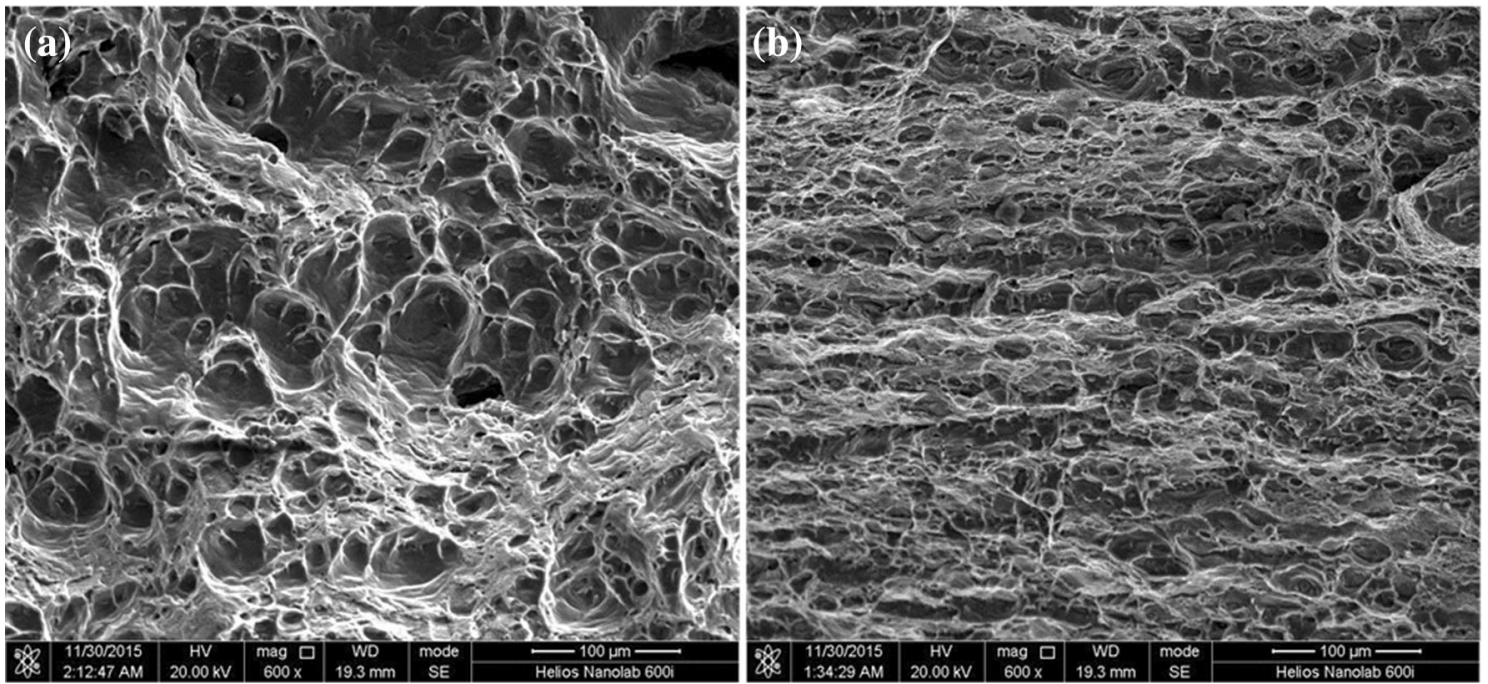

Fig. 7 Fracture morphologies of the final rupture regions: a $\mathrm{Al}-\mathrm{Zn}-\mathrm{Mg}-\mathrm{AS}$ joint, $\mathbf{b} \mathrm{Al}-\mathrm{Mg}-\mathrm{Si}-\mathrm{AS}$ joint 


\subsection{Effect of the Microstructure on the Fracture Mechanism}

For the Al-Zn-Mg-AS joints, the fracture position at the HAZ region locates about $15 \mathrm{~mm}$ from the joint centerline. For the $\mathrm{Al}-\mathrm{Mg}-\mathrm{Si}-\mathrm{AS}$ joints, the fracture position locates about $12 \mathrm{~mm}$ position from the joint centerline. To further investigate effect of the microstructure on the fracture mechanism, TEM photographs of the secondary phase particles at the fracture region are shown in Fig. 8.

For the $\mathrm{Al}-\mathrm{Zn}-\mathrm{Mg}-\mathrm{AS}$ joints, the precipitated phases are mainly the AlFeMnSi or AlMnCrSi phases and the $\beta^{\prime}$ phase owns sizes about $0.5-0.8 \mu \mathrm{m}$. For the $\mathrm{Al}-\mathrm{Mg}-\mathrm{Si}-\mathrm{AS}$ joints, similar precipitated phases can be observed with smaller $\beta^{\prime}$ phase, which owns sizes about $0.3-0.5 \mu \mathrm{m}$. Moreover, it can be seen that quantity of the $\beta^{\prime}$ phase on the $\mathrm{Al}-\mathrm{Mg}-\mathrm{Si}-\mathrm{AS}$ joint is more than that on the $\mathrm{Al}-\mathrm{Zn}-\mathrm{Mg}-$ AS joints. Crack sources can be divided into surface crack source and internal crack source. Without regard to the volume defect, internal crack sources always initiate from the coarse secondary phase particles. Similarly, during the crack propagating period, microstructure feature plays an important role in the propagation speed. Coarse secondary phase particle more easily results in stress concentration and then breaks or drops from the BM, which is beneficial to crack propagation.

For submicron secondary phase particle, when microcrack evolves into mechanical small crack, bridging effect of the secondary phase particles will slow down the crack propagation speed due to crack closure effect, since the crack tip opening displacement (CMOD) is at submicron level. Nakai and Eto [23] found out that for 2024 aluminum alloy, crack propagation speed decreased with increasing the sizes and distances of the secondary phase particles. And coarser secondary phase particles resulted in rougher fracture morphologies. Figure 9 shows the fracture morphologies of the two different joints, in which the photographs are both taken where the fatigue striations spacing is $0.6 \mu \mathrm{m}$. It can be seen that rougher fracture morphologies can be attained on the Al-Zn-Mg-AS joint (Fig. 9a). Only indistinct fatigue striations are observed in Fig. 9a. By contrast, more obvious fatigue striations are observed in Fig. 9b, illustrating the slight effect of the secondary phase particle. The fracture morphologies in Fig. 9 are in agreement with the TEM photographs in Fig. 8.

According to the crack closure argument, during the tension-tension fatigue test, the real factor determining the crack propagation speed is the effective value of stress intensity factor range $\Delta K_{\text {eff. }}$ Under repeated loading, crack tip region will plastically yield and tension stress will be formed. Hence, during unloading period, compressive stress $\sigma_{\mathrm{F}}$ is formed when the crack is closed. In the next loading process, crack will open and propagate only if the loading is bigger than $\sigma_{\mathrm{F}}$. Hence, now the maximum effective stress intensity factor range is $\Delta K_{\text {eff }}=\Delta K_{\max }-\Delta F_{\mathrm{F}}$.

At the beginning of the crack propagation stage, crack tip opening displacement (CMOD) is at the same order of magnitudes with the secondary phase particles. Crack closure argument appears at the crack tip. When the secondary phase particle appears at the crack end, it will come into contact with the crack surface, resulting in advanced closure. At the same time, the original $\sigma_{\mathrm{F}}$ at the crack tip
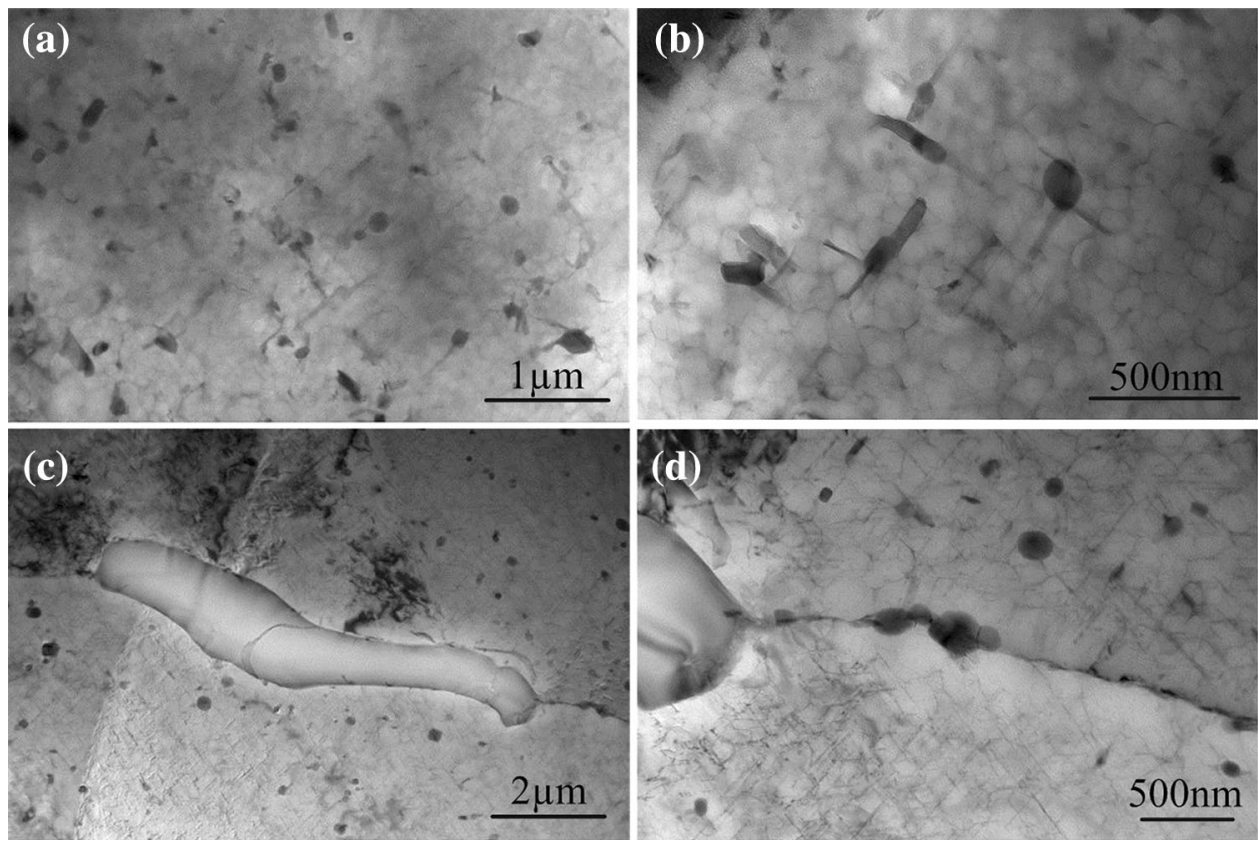

Fig. 8 TEM photographs of the fracture region: a Al-Zn-Mg-AS joint, $\mathbf{b}$ its magnified view, $\mathbf{c}$ Al-Mg-Si-AS joint, $\mathbf{d}$ its magnified view 

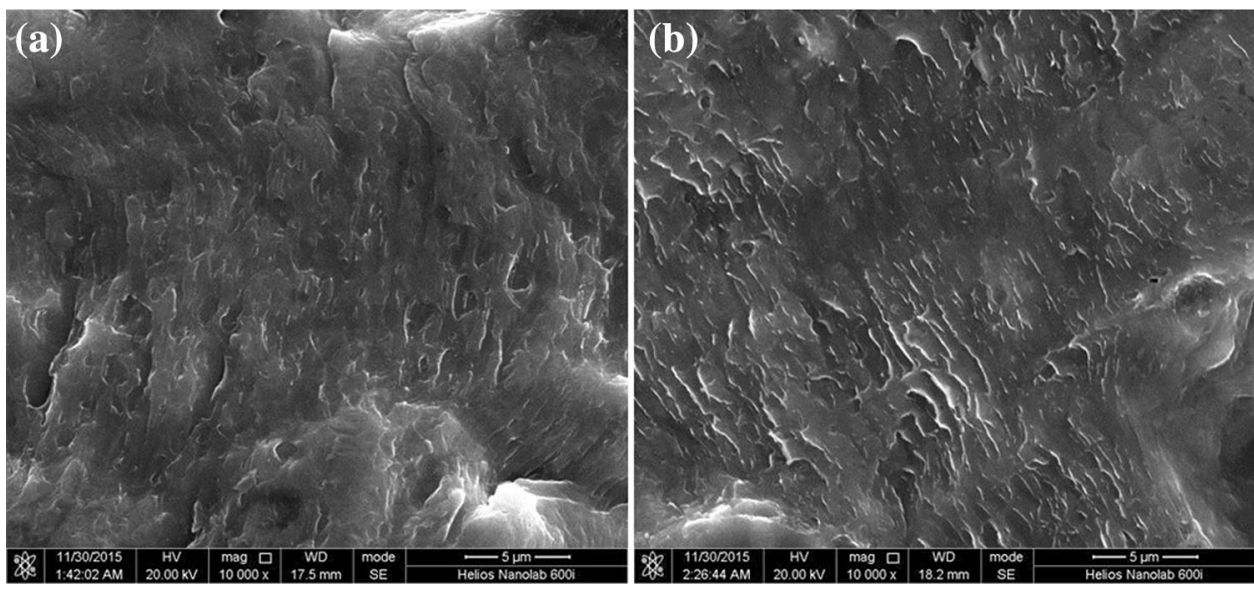

Fig. 9 Crack propagation when the fatigue striation spacing is $0.6 \mu \mathrm{m}$ : a $\mathrm{Al}-\mathrm{Zn}-\mathrm{Mg}-\mathrm{AS}$ joint, $\mathbf{b} \mathrm{Al}-\mathrm{Mg}-\mathrm{Si}-\mathrm{AS}$ joint

reduces the stress amplitude from $\Delta \sigma=\sigma_{\max }-\sigma_{\min }$ to $\Delta \sigma=\sigma_{\max }-\sigma_{\min }-\sigma_{\mathrm{F}}$. Hence, the driving force at the crack tip is reduced. Bigger secondary phase particles can result into lower crack propagation speed.

Based on the above-mentioned discussion, the following conclusions can be drawn. Size of the secondary phase particle on the $\mathrm{Al}-\mathrm{Zn}-\mathrm{Mg}-\mathrm{AS}$ joint is bigger, and the secondary phase particles are more dispersed distributed. Coarser fracture morphology can be obtained in the Al$\mathrm{Zn}-\mathrm{Mg}-\mathrm{AS}$ joint. Crack closure effect is easier to happen in the $\mathrm{Al}-\mathrm{Zn}-\mathrm{Mg}-\mathrm{AS}$ joint, and better fatigue properties can be obtained.

\section{Conclusions}

In the present study, fatigue properties of dissimilar $\mathrm{Al}-\mathrm{Mg}-$ $\mathrm{Si} / \mathrm{Al}-\mathrm{Zn}-\mathrm{Mg}$ aluminum alloys FSW joints were investigated. Based on the fracture morphologies and microstructure observations, following conclusions can be drawn:

1. Fatigue properties of the $\mathrm{Al}-\mathrm{Zn}-\mathrm{Mg}-\mathrm{AS}$ joints are better than that of the $\mathrm{Al}-\mathrm{Mg}-\mathrm{Si}-\mathrm{AS}$ joints. Using different configurations, all joints fracture at the HAZ region at the $\mathrm{Al}-\mathrm{Mg}-\mathrm{Si}$ alloy side. Based on the $S_{-}$ $N$ curves, the fatigue strengths of $\mathrm{Al}-\mathrm{Zn}-\mathrm{Mg}-\mathrm{AS}$ and $\mathrm{Al}-\mathrm{Mg}-\mathrm{Si}-\mathrm{AS}$ joint are, respectively, 105.6 and $90.1 \mathrm{MPa}$ at $10^{7}$ cycles.

2. The secondary phase particle at the fracture region is characterized by submicron $\beta^{\prime}$ phase. For the $\mathrm{Al}-\mathrm{Zn}-$ $\mathrm{Mg}-\mathrm{AS}$ joint, the size of the $\beta^{\prime}$ phase is bigger and the $\beta^{\prime}$ phases are more disperse distributed, which is beneficial to bridging effect. Therefore, the Al-Zn$\mathrm{Mg}-\mathrm{AS}$ joints own better fatigue properties.

Acknowledgements This work is supported by the International S\&T Cooperation Program of China (ISTCP, No. 2012DFR50580).

\section{References}

[1] L. John Baruch, R. Raju, V. Balasubramanian, A.G. Rao, I. Dinaharan, Acta Metall. Sin. (Engl. Lett.) 29(5), 431 (2016)

[2] S.D. Ji, Y.Y. Jin, Y.M. Yue, S.S. Gao, Y.X. Huang, L. Wang, J. Mater. Sci. Technol. 29, 955 (2013)

[3] B.S. Naik, D.L. Chen, X. Cao, P. Wanjara, Metall. Mater. Trans. A 44, 3732 (2013)

[4] A.M. El-Batahgy, T. Miura, R. Ueji, H. Fujii, Mater. Sci. Eng. A 651, 904 (2016)

[5] L. Zhou, H.J. Liu, Q.W. Liu, Mater. Des. 31, 2631 (2010)

[6] X. Fei, X. Jin, Y. Ye, T. Xiu, H. Yang, Mater. Sci. Eng. A 653, 43 (2016)

[7] Y. Wei, J. Li, J. Xiong, F. Huang, F. Zhang, S.H. Raza, Mater. Charact. 71, 1 (2012)

[8] S. Ji, Z. Li, L. Zhang, Z. Zhou, P. Chai, Mater. Des. 103, 160 (2016)

[9] V. Firouzdor, S. Kou, Metall. Mater. Trans. A 41, 3238 (2010)

[10] C. Deng, H. Wang, B. Gong, X. Li, Z. Lei, Int. J. Fatigue 83, 100 (2016)

[11] Z. Zhang, W. Li, F. Wang, J. Li, Mater. Lett. 162, 94 (2016)

[12] H. Barekatain, M. Kazeminezhad, A.H. Kokabi, J. Mater. Sci. Technol. 30, 826 (2014)

[13] Q.L. Dai, Z.F. Liang, G.Q. Chen, L.C. Meng, Q.Y. Shi, Mater. Sci. Eng. A 580, 184 (2013)

[14] G. D’Urso, C. Giardini, S. Lorenzi, T. Pastore, J. Mater. Process. Technol. 214, 2075 (2014)

[15] H.M. Rao, J.B. Jordon, B. Ghaffari, X. Su, A.K. Khosrovaneh, M.E. Barkey, W. Yuan, M. Guo, Int. J. Fatigue 82, 737 (2016)

[16] Z. Shen, Y. Ding, J. Chen, A.P. Gerlich, Int. J. Fatigue 92, 78 (2016)

[17] T.S. Srivatsan, M. Kuruvilla, L. Park, Mater. Sci. Eng. A 527, 435 (2010)

[18] E. Maggiolini, R. Tovo, L. Susmel, M.N. James, D.G. Hattingh, Mater. Sci. Eng. A 92(2), 478 (2016)

[19] P. Cavaliere, G.L. Rossi, R. Di Sante, M. Moretti, Int. J. Fatigue 30(1), 198 (2008)

[20] M. Bahrami, N. Helmi, K. Dehghani, M.K.B. Givi, Mater. Sci. Eng. A 595(10), 173 (2014)

[21] S.D. Ji, X.C. Meng, J.G. Liu, L.G. Zhang, S.S. Gao, Mater. Des. 62, 113 (2014)

[22] M. Kadlec, R. Ruzek, L. Novakova, Int. J. Fatigue 74, 7 (2015)

[23] M. Nakai, T. Eto, Mater. Sci. Eng. A 285, 62 (2000) 